\title{
The impact of Gouin Reservoir management on the ecohydrological drought characteristics of streamflow in the Saint-Maurice River (Quebec, Canada)
}

\author{
R. Landry \& A. A. Assani \\ Département des Sciences de L'Environnement, \\ Université du Québec à Trois-Rivières, Canada
}

\begin{abstract}
We analyzed the impacts of the Gouin Reservoir, built on the Saint-Maurice River, in Quebec, on the magnitude and frequency of ecohydrological drought. Magnitude values, calculated as the difference between measured low flow and the ecological compensation flow, have increased significantly over time as a result of decreasing amounts of snow, while frequency has not changed significantly over time. The study suggests that a new mode of dam management is required for the Gouin Reservoir to ensure the preservation of fish habitats downstream from the reservoir, and that mode must take into account the decreasing amount of snow in the watershed.

Keywords: ecohydrological drought, Gouin Reservoir, ecological compensation flows, Lombard method.
\end{abstract}

\section{Introduction}

There is growing agreement about the fact that climate warming will lead to enhanced extreme hydroclimate phenomena. Thus, even in regions generally described as wet such as Quebec, the drought frequency will increase as a result of a decreasing amounts of snow (e.g., Brown [1]; Guerfi et al. [2]) and increased evapotranspiration resulting from higher winter and summer temperatures (Boyer et al. [3]; Yagouti et al. [4]). Several recent studies have highlighted trends of decreasing streamflow and water levels in several regions of Quebec (e.g., Assani et al. [5-7]). This decrease is even greater downstream from dams because of the 
large volumes of water stored in reservoirs during low rainfall years (e.g., Assani et al. [8]).

In scientific terms, however, no clear and universal definition of drought exists. In hydrology, many indices and criteria are proposed in the literature to define drought (e.g., Mishra and Singh [9, 10]; Tsarikis et al. [11]; Van Huijgevoor et al. [12]). To date, however, none of these ideas take into account the ecological impacts of this extreme hydrological phenomenon. To address the issue, the main goal of this study is to introduce a new drought concept (ecohydrological drought) which allows a clear definition of the drought phenomenon from an ecohydrological standpoint by including the potential ecological impacts of hydrological drought in river systems. This is a novel idea because it incorporates into the definition of drought the ecological compensation flows developed to protect the ecological integrity of natural and dam-regulated rivers in Quebec. This concept is applied to the quantification of the impacts of the Gouin Reservoir on ecohydrological drought. Built in the headwaters of the Saint-Maurice River watersheds, one of the main north shore tributaries of the St. Lawrence River, this reservoir is one of the largest in Quebec in terms of its capacity for storing water in the spring. Until now, the potential impacts of this large storage capacity on fish populations have not been analyzed.

\section{Methods}

\subsection{Description of the Saint-Maurice River watershed and Gouin Reservoir}

The Saint-Maurice River, a north shore tributary of the St. Lawrence River, drains a $43,427 \mathrm{~km}^{2}$ watershed (fig. 1) and cuts through two geological formations with differing strength: the Canadian Shield, comprising various gneissic units consisting of hard, impermeable and generally acidic rocks, and the St. Lawrence Lowlands, comprising predominantly alkaline schist and clayey limestone. In the Canadian Shield, the longitudinal profile of the river is marked by abrupt breaks in slope at the foot of which dams and hydroelectric plants have been built. The climate is sub-polar continental, with annual precipitations on the order of $1,000 \mathrm{~m}$ and a mean annual temperature of $4^{\circ} \mathrm{C}$. Most of the watershed is covered by deciduous forest essentially comprised of sugar maple-yellow birch stands. In terms of land use, human activity is essentially restricted to logging. Farming takes place only in the St. Lawrence Lowlands, which make up a third of the total surface area of the watershed. Data on daily flows released downstream from the Gouin Reservoir were taken from the Environment Canada website, except for data after 1994, which were kindly provided by Hydro-Quebec. It should be mentioned that available streamflow data used in the study go back to January 1930. There are no precipitation or temperature data measured continuously in the Gouin Reservoir area of influence.

To support industrialization, the immense Gouin Reservoir was built at the head of the Saint-Maurice River watershed in 1918 to supply hydroelectric power plants located downstream. These plants supply hydroelectric power in winter, when precipitation falls almost exclusively as snow, to industrial facilities and 


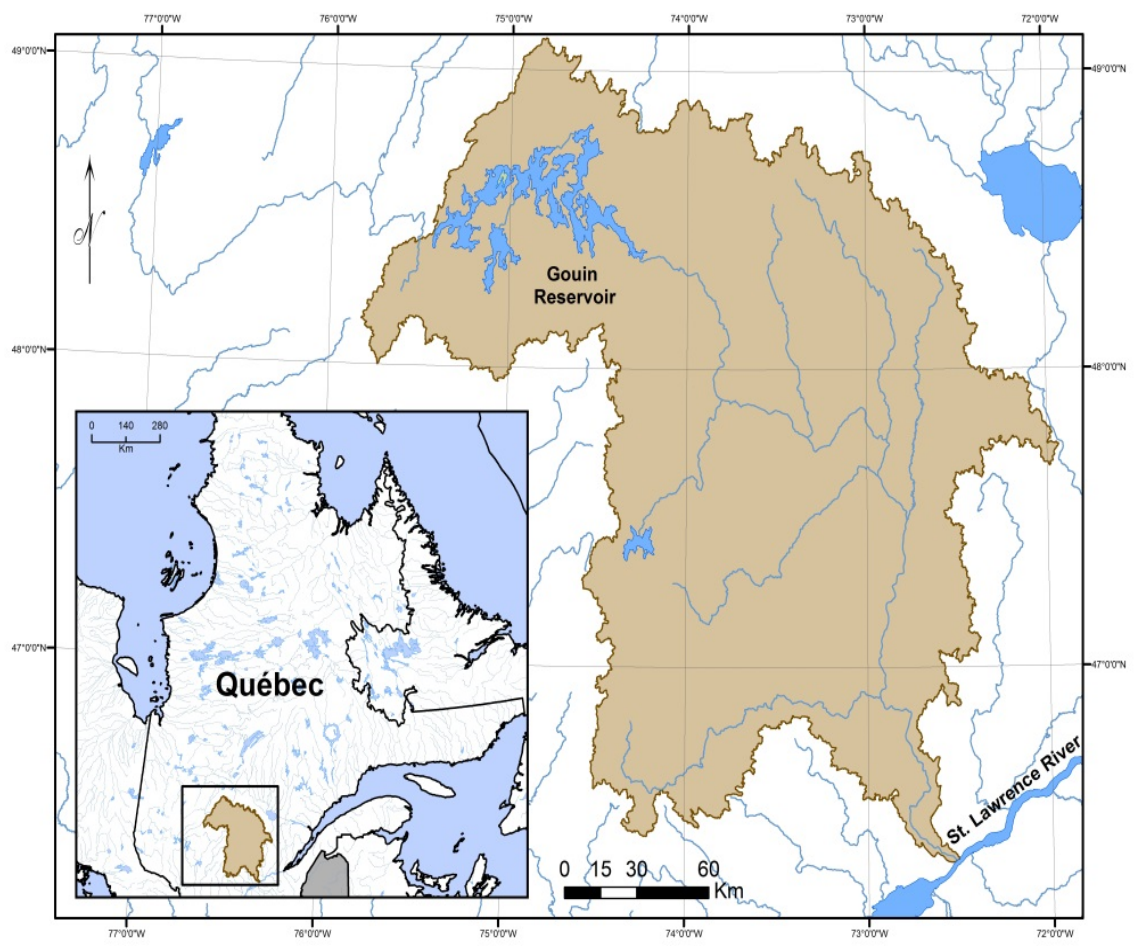

Figure 1: Location of the Gouin Reservoir in the Saint-Maurice River watershed.

towns in the St. Lawrence Lowlands. To increase reservoir capacity, two rivers (the Susie and Mégiscane) that used to flow in the Hudson Bay watershed to the north were diverted to the reservoir. The Gouin Reservoir, which is $26 \mathrm{~m}$ high, has a maximum storage capacity of around $8.6 \mathrm{~km}^{3}$ and covers 142.7 ha. The storage of large amounts of water in the reservoir in the spring, during snowmelt, has led to an inversion of the natural hydrologic cycle, with maximum flows occurring in winter, to supply hydroelectric power plants, and minimum flows occurring in the spring, when snowmelt water is stored in the reservoir. Streamflow data were taken from the Environnement Canada website [13].

\subsection{Definition of ecohydrological drought and the ecohydrological drought index}

Ecohydrological drought occurs when measured daily flows (Qd) downstream from a dam or in a natural river are lower than the ecological compensation flow (Qec). In Quebec, this compensation flow is defined as the minimum flow required to maintain fish habitats at a level deemed acceptable (FAPAQ [14]). The ecohydrological drought index (Seh) is therefore defined by the following formula: 


$$
\text { Seh }=\text { Qd }- \text { Qec }<0
$$

This index may be used to calculate the following characteristics of ecohydrological drought:

Magnitude, which is the difference between measured daily flow and the estimated ecological compensation flow under natural conditions (absence of a dam). To avoid negative values of magnitude, the following formula is used:

$$
\mathrm{Seh}=(\mathrm{Qec}-\mathrm{Qd}) / \mathrm{Qec}
$$

This formula is a measure of the difference between the ecological compensation flow and daily flow measured in the river, expressed as a ratio (R, in \%). Only flows lower than the ecological compensation flow are considered.

Frequency, which is the total number of days during which measured daily flows are lower than the estimated ecological compensation flow for a given timescale (annual, seasonal, monthly).

\subsection{Estimating ecological compensation flows in Quebec}

The estimation of ecological compensation flows has been described in detail by Lajoie et al. [15]. The main points of this description are mentioned here. There are many methods available for estimating compensation flows. In this study, the method proposed by Belzile et al. [16] is used for the following reasons:

- It is one of the methods recommended by the FAPAQ [14] and the Quebec Ministère de l'Environnement for estimating compensation flows in Quebec and it takes into account ecological, hydrological and geographic factors specific to streams in Quebec, as well as species present in all Quebec watersheds and their critical life stages, something that the other hydrological methods do not do. In addition, although its application is easy, it does account for the various life cycle stages of different fish species in Quebec.

- It is the only method with which ecological compensation flows for any river in southern Quebec may be estimated based solely on flow values (hydrological method) and watershed surface area. As a result, it is the only method with which compensation flows downstream from all dams in Quebec may be estimated using only watershed surface area, without field measurements.

Methods used to determine ecological compensation flows are described in detail by Belzile et al. [16]. These are advanced hydrological methods adapted for Quebec to match specific needs of diverse hydroecological regions with a goal to protect fish habitats in general and target fish species in particular at different times of the years (months, seasons). Target species are those that require more attention than others due to their low abundance, at-risk status, value for sports or commercial fishing or sensitivity to changes in natural flow conditions at specific stages of their life cycle. The number of target species differs between regions. For more details about these species, the reader is referred to Belzile et al. [16]. These authors proposed six ecological compensation flow indices that take into 
account the hydrological regions and critical life stages of target species in the course of a year.

To estimate ecological compensation flows downstream from the Gouin Reservoir using the Belzile et al. [16] method, we used the following formula:

$$
\mathrm{Qec}=\mathrm{e}^{\mathrm{k}} \cdot \mathrm{S}^{\mathrm{a}}
$$

where Qec is the ecological compensation flow (in $\mathrm{m}^{3} / \mathrm{s}$ ) to be estimated at the Gouin Reservoir, S is the surface area of the Saint-Maurice River watershed upstream from the Gouin Reservoir (including the area of the two diverted rivers), which is $9,473 \mathrm{~km}^{2}, k$ and $a$ are regionalized and seasonalized exponents (constants), and e is a constant (natural logarithm). Values of $\mathrm{k}$ and a depend on the ecological and hydrological regions, the timescale of analysis, and the critical life cycle stages of target fish species in the different ecohydrological regions. They were calculated by Belzile et al. [16] as a function of these different factors. At the annual scale, for the Gouin Reservoir, values of $\mathrm{k}$ and a are 0.995 and -4.56 , respectively.

Although estimating compensation flows based only on watershed surface area may seem simplistic, Belzile et al. [16] justify this approach by the fact that, "in all ecohydrological regions, knowledge of watershed surface area upstream from the point where flow is to be estimated may, in and of itself, be sufficient to determine this flow. The other variables add little information or precision to the estimation". This argument was also mentioned by Anctil et al. [17] and Anctil and Coulibaly [18] for flood and low flows in Quebec. These authors recommended using watershed surface area to estimate maximum annual flows and 7-day low flows. Moreover, streamflow and watershed surface area are strongly correlated in Quebec, regardless of the scale of analysis (Assani and Tardif [19]).

\subsection{Statistical analysis}

The first step consisted in producing chronological series of the two characteristics of ecohydrological drought as defined in section 2.2. It is important to specify that ecohydrological drought magnitude was only derived with respect to the lowest minimum flow measured in a given hydrological year, defined as the period from January to December, in order to produce a single magnitude value per year, expressed as the difference between measured flow and compensation flow, in percent. This value is the highest ecohydrological drought magnitude observed during a given year.

The second step consisted in analyzing the ecohydrological drought magnitude and frequency (in days) time series with the Lombard method (Lombard [20]; Quessy et al. [21]), to highlight changes in mean values of these two characteristics over time. The Lombard method is increasingly used in the scientific literature and, unlike other breakpoint detection methods, it is a general method that allows the detection of both sharp and progressive shifts in mean or variance values. It is the most powerful method for detecting any change in mean or variance over time (see Quessy et al. [21]). The Lombard method was applied to standardized magnitude and frequency data. According to the method, the null hypothesis (no 
shift in mean values of the hydrological series) is rejected when the Sn value derived for observational data is greater than 0.0403 , which is the theoretical critical value of the Lombard statistic (see Lombard [20]), at the 5\% probability level.

\section{Results and discussion}

\subsection{Analysis of hydrological drought characteristics downstream from the Gouin Reservoir}

As far as magnitude is concerned, values of the difference (expressed as a ratio, R) between ecological compensation flow and the lowest minimum flow released downstream from the Gouin Reservoir are shown in fig. 2, which shows that all difference values are positive, implying that the lowest minimum flow released downstream from the reservoir each year is lower than the ecological compensation flow. For frequency, the number of days when measured flows are less than the compensation flow ranges from 49 to 241 days, with a mean value of 137 days (fig. 3 ).

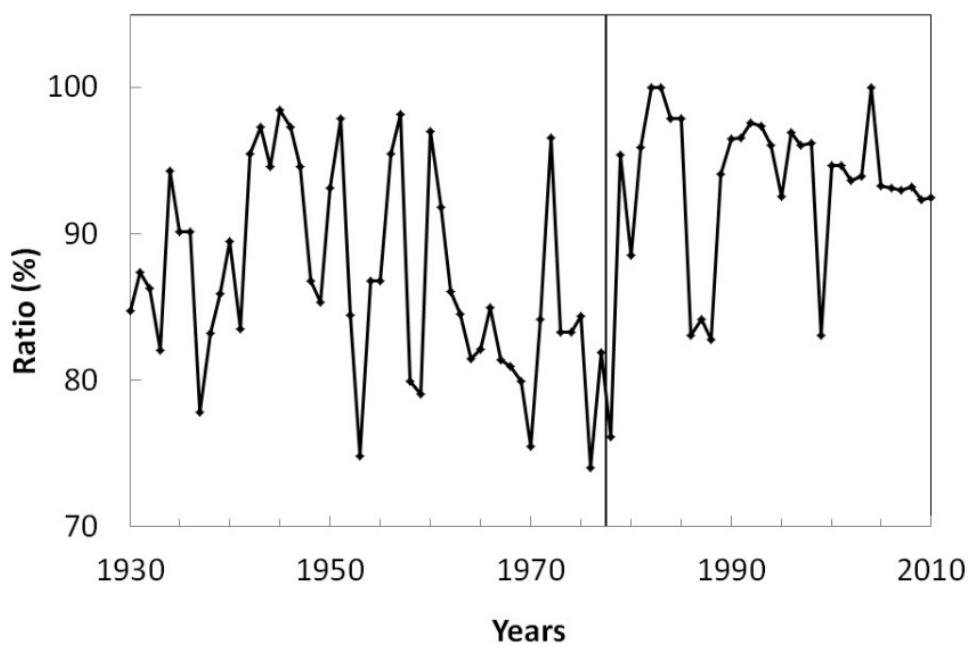

Figure 2: Temporal variability of ratio values (the difference between ecological compensation flows and annual minimum daily flow) downstream from the Gouin Reservoir (1930-2010). The vertical bar shows year of shift in mean obtained using the Lombard method.

Results of the Lombard method (shown in table 1), reveal that differences between measured flows and compensation flows increase significantly over time. In other words, the magnitude of the lowest minimum flows released each year downstream from the Gouin Reservoir has decreased significantly over time, because the ecological compensation flow does not change over time. In contrast, 
the frequency of days when flows are lower than the ecological compensation flow has not changed significantly over time.

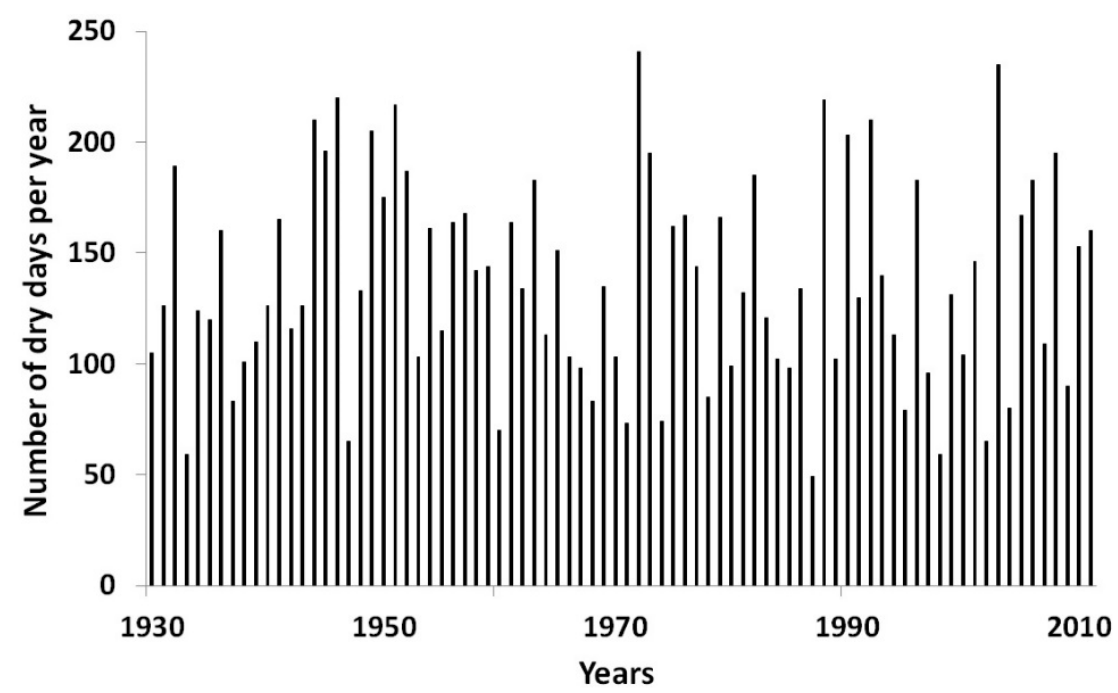

Figure 3: Temporal variability of ecohydrological drought frequency (total number of dry days each year) downstream from the Gouin Reservoir (1930-2010).

Table 1: Results of the stationarity analysis of ecohydrological drought magnitude (difference) and frequency using the Lombard method (1930-2011).

\begin{tabular}{|l|c|c|c|}
\hline Variables & Sn & T1 & T2 \\
\hline Magnitude (difference) & 0.0574 & 1977 & 1978 \\
\hline Frequency & 0.0036 & - & - \\
\hline
\end{tabular}

$\mathrm{Sn}=$ Lombard test statistic. Statistically significant $\mathrm{Sn}$ values at the $5 \%$ levels are shown in bold. $\mathrm{T} 1$ and $\mathrm{T} 2$ = dates of start and end, respectively, of shift in mean.

\section{Discussion and conclusion}

This study introduces a new concept of drought which incorporates the potential impacts of drought on fish habitats. This new concept is based on compensation flows, meaning the flows that must absolutely be maintained downstream from a dam or reservoir to protect these habitats. Application of the concept clearly shows that, downstream from the Gouin Reservoir, ecological drought is a yearly 
occurrence that lasts more than one month on average. Moreover, the difference between the compensation flow and the annual minimum daily flow (the lowest flow released downstream from the reservoir during a given year) has increased significantly over time. This increase may be explained by the decrease in amount of snow observed in many watersheds in southern Quebec (Guerfi et al. [2]), resulting in larger amounts of water being stored in reservoirs, thus decreasing the magnitude of annual minimum daily flows. This flow management mode leads to a higher risk of compromising the life cycle of many fish species downstream from the reservoir. Dam managers must therefore take into account the trends described in this study in order to reduce risks to fish species. For the Gouin Reservoir, this requires the development of a new management mode that accounts for the decrease in amount of snow in the watershed, in order to protect fish species downstream from the reservoir.

\section{References}

[1] Brown RD. 2010. Analysis of snow cover variability and change in Québec, 1948-2005. Hydrol Process 24: 1929-1954.

[2] Guerfi N, Assani AA, Mesfioui M, Kinnard C. 2015. Comparison of the temporal variability of winter daily extreme temperatures and precipitations in southern Quebec (Canada) using the Lombard and coupla methods. Inter. J Climatol. DOI: 10.1002/joc.4282 (in press).

[3] Boyer C, Chaumont D, Chartier I, Roy AG. 2010. Impact of climate change on the hydrology of St.Lawrence tributaries. J Hydrol. 384: 65-83.

[4] Yagouti A, Boulet G, Vincent L, Vescovi L, Mekis E. 2008. Observed changes in daily temperature and precipitation indices for southern Québec, 1960-2005. Atmos-Ocean. 46: 243-256.

[5] Assani AA, Landry R, Laurencelle M. 2013. Comparison of interannual variability modes and trends of seasonally precipitations and streamflow in Southern Quebec (Canada). River Res Applic 28:1740-1752.

[6] Assani AA, Landry R, Stacey B, Frenette JJ. 2014a. Analysis of the interannual variability of annual daily extreme water levels in the St. Lawrence River and Lake Ontario from 1918 to 2010. Hydrol. Process. 28: 4011-4022.

[7] Assani AA, Landry R, Labrèche M, Frenette J-J, Gratton D. $2014 \mathrm{~b}$. Temporal variability of monthly daily Extreme water levels in the St.Lawrence river at the Sorel station from 1912 to 2010. Water 6: 196-212.

[8] Assani AA, Chalifour A, Légaré G, Manouane C-S, Leroux D. 2011. Temporal regionalization of 7-day low flows in the St. Lawrence watershed in Quebec (Canada). Water Res Manage 25: 3559-3574.

[9] Mishra AK, Singh VP. 2010. A review of drought concepts. J Hydrol. 391: 202-216.

[10] Mishra AK, Sing VP. 2011. Drought modeling- A review. J Hydrol. 403: $157-175$. 
[11] Tsarikis G, Pangalon D, Vangelis H. 2007. Regional drought assessment based on the reconnaissance drought index (RDI). Water Resourc. Manage 21: 821-833.

[12] Van Huijgevoor MHJ, Hazenberg P, van Lanen HAJ, Uijlenhoet R. 2012. A generic method for hydrological drought identification across different climate regions. Hydrol. Earth Syst. Sci. 16: 2437-2451.

[13] Environnement Canada (http://www.wsc.ec.gc.ca/applications/H2O/indexfra.cfm, accessed on 15 October 2013).

[14] FAPAQ (Faune et Parcs Québec). 1999. Politique de débits réservés écologiques pour la protection du poisson et de ses habitats. Ministère de l'environnement et de la faune du Québec, Direction de la faune et des habitats, Québec.

[15] Lajoie F, Assani AA, Matteau M, Mesfioui M, Roy AG. 2006. Comparaison entre débits réservés écologiques et débits lâchés en aval des barrages au Québec: influence du mode de gestion des barrages, de la taille des bassins versants et de la saison. Water Qual J Can. 41: 263-274.

[16] Belzile L, Bérubé P, Hoang VD, Leclerc M. 1997. Méthode écohydrologique de détermination des débits réservés pour la protection des habitats du poisson dans les rivières du Québec. Rapport présenté par l'INRS-Eau et le Groupe-conseil Génivar inc. au ministère de l'Environnement et de la Faune et à Pêches et Océans Canada. 83 pp. +8 annexes.

[17] Anctil, F., Martle, F., Hoang, V.D., 1998. Analyse régionale des crues journalières de la province du Québec. Canadian Journal of Civil Engineering 25, 125-146.

[18] Anctil F, Coulibaly P. 2004. Wavelet analysis of the interannual variability in southern Quebec streamflow. Journal of Climate 17: 163-173.

[19] Assani AA, Tardif S. 2005. Classification, characterisation et facteurs de variabilité spatial des regimes hydrologiques naturels au Québec (Canada). Approche éco-géographique. Revue des Sciences de l'Eau 18: 247-266.

[20] Lombard F. 1987. Rank tests for changepoint problems. Biometrika 74: 615-624.

[21] Quessy J-F, Favre A-C, Saïd M, Champagne M. 2011. Statistical inference in Lombard's smooth-change model. Environmetrics 22: 882-893. 